Accelerator Department

BROOKHAVEN NAT IONAL LABORATORY

Associated Universities, Inc.

Uptom, New York 11973

AGS DIVISION TECHNICAL NOTE

No. 134

AGS CABLE TELEVISION SYSTEM

R. Sanders

May 20, 1977

Over the last 15 years, the cost of a baseband closed circuit television system (CCTV), has dropped significantly, making it feasible for use in scientific facilities such as the AGS. During the latter part of this period, new developments in community antenna television systems (CATV), has made cable TV an attractive alternative to CCTV systems.

Without going into extensive details of comparing the advantages or disadvantages of CCTV vs. CATV, it is only necessary to consider how CCTV at the AGS, has grown in a haphazard way, with its never ending problems of cable mismatching, improper terminations, no equalization, and noise pickup. A CATV system requires only one cable, can pass carriers in both directions simultaneously, does not require video equalization to restore picture quality, and provides sufficient isolation so that careless impedance matching at the TV receiver has little or no effect on the system, and in turn, other users. A cable TV system has been chosen for the new AGS information system.

There are many types of CATV distribution systems and one of the simpler forms has been selected for use at the AGS, and will be installed during the summer of 1977 . The new system will actually be two separate systems having a number of shared and separate channels. One system which has been termed the "Operations System", will provide two-way communications between the AGS Main Control Room, MG-RF Building area, CLIF house and Medical Facilitty area, and the Linac Control room. The other system, called the "User System" will provide two-way communications between the AGS Main Control Room, the East.Experimental buildings and the Bubble Chamber. 
The "Operations System" will have a11 11 forward channels. Three of these channels will share the same video with the "Users System", i.e. status displays, test signals and video taped program material. Four channels will carry video originating in Building 911. The remaining four channels will be VHF channels converted from reverse transmission subchannels, whose modulators can be located anywhere in the distribution system from Building 911 to the Iinac control room.

The "User System" will have 13 forward channels. Three channels are the aforementioned channels that are common to both systems. Seven channels will carry video originating in Building 911. The remaining three channels will be VHF channels converted from reverse transmission subchannels, whose modulators can be located anywhere in the distribution system including Building 911, the East Experimental Buildings and the Bubble Chamber.

For clarity, a tabulation of channels is as follows:

Users System

\section{Separate Channels}

\begin{tabular}{|c|c|c|c|}
\hline Input & Output & Input & Output \\
\hline$\underset{" \text { Video }}{ }$ & $\begin{array}{cc}\text { Ch. } & 2 \\
\text { "I } & 3\end{array}$ & ${ }^{\text {Video }}$ & "Ch. 13 \\
\hline$"$ & $"$ & $"$ & " $\quad \mathrm{K}$ \\
\hline$"$ & " 5 & $"$ & L \\
\hline$"$ & "10 & & \\
\hline$"$ & " 11 & & \\
\hline " & " 13 & & \\
\hline
\end{tabular}

\section{Operations System}

\section{Common Channe 1s}

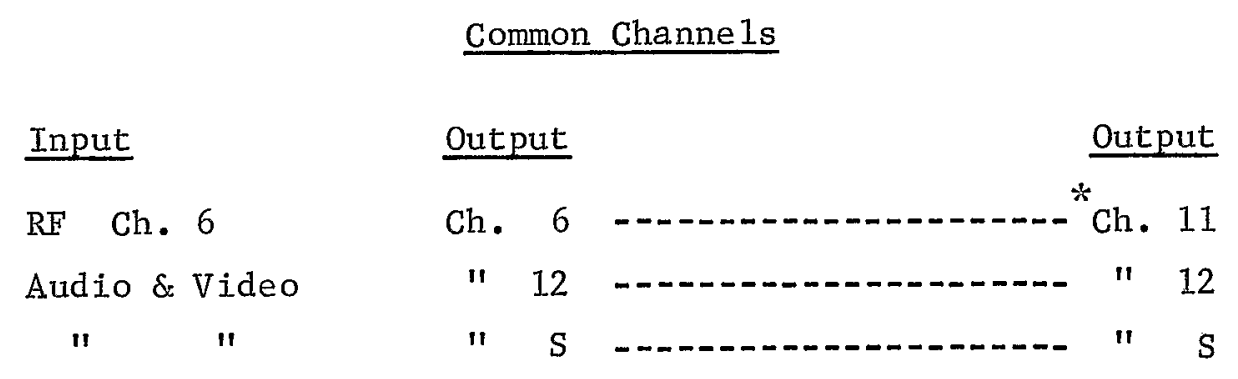

Reverse/Forward Channels

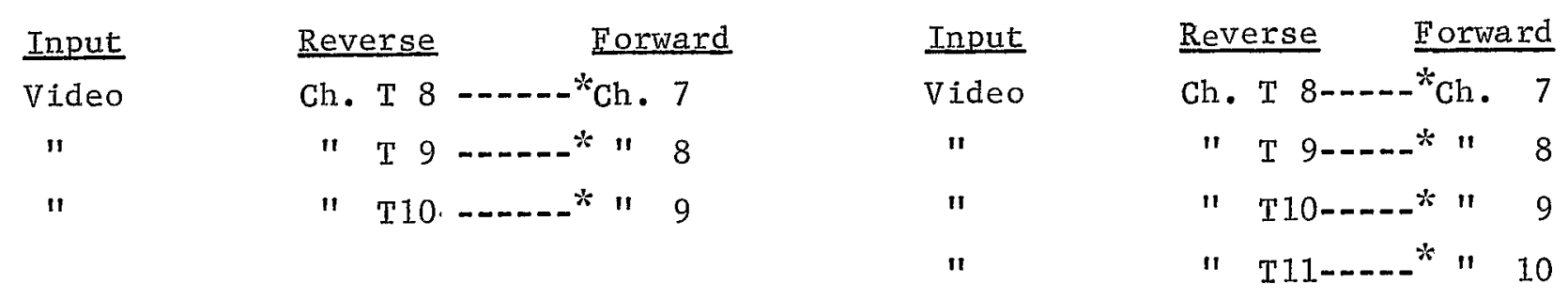

* Denotes frequency conversion by heterodyne signal processor. 
The channels with letter designations are called super channels, and are located above Channe1 13 in the frequency range from 216 to $300 \mathrm{MHz}$. Converters must be used with the television receivers to reach these channeis.

The channels with letter-number designations such as T8 or T9, are called reverse or subchannels. These channels are converted by signal processors to standard VHF channels and then retransmitted.

Both systems can be expanded to include more channels as determined by future needs. The type of system used as the "Operations System", is called a mid-split system, and has its forward and reverse channel split between channels 6 and 7 . With the split placed in the middle of the VHF band this system can accommodate 21 forward channels and 12 reverse channels. The "Users System" is called a sub-split system, and has its forward and reverse split between $30 \mathrm{MHz}$ and $50 \mathrm{MHz}$ (below channe1 2). A sub-split system can accommodate 36 forward and 4 reverse channels.

Thesable distribution system in the experimental buildings wil1 provide user service outlets on alternate building columns so that the "drop" cables to TV sets will be less than 100 feet long in most cases. Connections in other areas will be made directly to the line tap device. A11 signal levels at taps and outlets will be $10 \mathrm{db}$ above what is considered normal receiver input levels, to take care of line and splitter losses.

A11 signa1 reception outside of Building 911 wil1 be on standard. black and white television receivers except in certain unattended 1ocations where video monitors will be used in conjunction with TV demodulators located in attended areas.

The AGS has an extensive supply of relatively new CCTV equipment including cameras, monitors, distribution amplifiers and video switching equipment. This equipment will still be used to carry video from the experimental areas to the AGS Main Control Room and TV headened areas. Also, the video system for status displays within Building 911 will also be retained, and a number of additional monitors will be added for convenience. If more status channels are added at some later date, they may be sequentially switched over the present CCTV system with 


\section{BROOKHAVEN NATIONAL LABORATORY \\ MEMORANDUM}

DATE: May 24, 1977

$\begin{array}{ll}\text { TO: } & \text { See Bellow: } \\ \text { FROM: } & \text { R.T. Sanders }\end{array}$

SUBJECT: AGS TV System

The attached Tech. Note outlines the new AGS TV system.

At this time only one channel (the status channe1), has been dedicated. The other channels will be assigned according to users and operations needs. We are requesting at this time, that after reading the Tech. Note, that you please jot down any ideas you might have pertaining to channe 1 allocations, as related to FEB, SEB and operations. Comments about additional status information, in-house generated and prepackaged program materials are also welcome.

Please forward comments to: R.T. Sanders - B1dg. 911-B.

\section{Attachment}

TO: :Accel Dept. S\&P

IET Experimenta1 Users

lisenR: Dryden

Phys R. Gottschalk

R. Rautera:

N. Samios

P. Wanderer 